\title{
Sistema imunológico de defesa em insetos: uma abordagem em lagartas da soja, Anticarsia gemmatalis Hübner (Lepidoptera: Noctuidae), resistentes ao AgMNPV
}

\section{Immunology defense system in insects: an approach in velvetbean catterpillar, Anticarsia gemmatalis Hübner (Lepidoptera: Noctuidae), AgMNPV-resistant}

\author{
Maria Cláudia Cordeiro de Negreiro ${ }^{1 *}$; Fábio Goulart de Andrade ${ }^{2}$; \\ Ângela Maria Ferreira Falleiros ${ }^{3}$
}

\section{Resumo}

Os insetos ocupam quase todos os nichos ecológicos e estão constantemente expostos ao ataque de inúmeros inimigos naturais, muitos dos quais são potencialmente patogênicos. Para sobreviver a esses ataques, os insetos desenvolveram eficiente sistema de defesa, representado pela espessa cutícula que os recobre, pelo sistema digestório e por células da hemolinfa, os hemócitos, que promovem a defesa celular. A lagarta da soja, Anticarsia gemmatalis, como praga desta cultura, demanda $60 \%$ das aplicações de inseticidas nas lavouras de soja nacionais. Com a utilização cada vez mais ampla do nucleopoliedrovirus Baculovirus anticarsia visando seu controle, estudos envolvendo o reconhecimento de corpos estranhos pelo sistema de defesa e sua destruição juntamente com o aparecimento de linhagens de lagartas resistentes, são suportes para metodologias que tornam o controle deste inseto-praga mais eficaz, até como prevenção para o surgimento de lagartas naturalmente resistentes no campo.

Palavras-chave: Anticarsia gemmatalis, hemócitos, resistência.

\begin{abstract}
The insects occupy almost all ecological niches and are constantly exposed to the attack of innumerable natural enemies, many of which are potentially pathogenic. To survive to these attacks, the insects had developed efficient defense systems, represented by outer cuticle, the digestory system and hemolymph cells, the hemocytes, that promote cellular defense. The velvetbean caterpillar, Anticarsia gemmatalis, as soybean pest crop, demand $60 \%$ of the insecticide applications in the national soybean crops. With the more and more use of the nucleopolihedrovirus Baculovirus anticarsia aiming at its control, studies involving the foreing body recognition and its destruction by the defense systems together with the appearance of resistant strains caterpillar are supports for methodologies that become the control of this more efficient, until as prevention for the appearing of caterpillar naturally resistant in the field.
\end{abstract}

Key words: Anticarsia gemmatalis, hemocytes, resistence.

\footnotetext{
Mestre em Agronomia, Docente do Departamento de Histologia CCB/UEL-PR. E-mail: mcnegreiro@uel.br

2 Mestre em Agronomia, Docente do Departamento de Histologia CCB/UEL-PR

3 Doutora em Ciências Biológicas, Docente do Departamento de Histologia CCB/UEL-PR. Autor para correspondência. E-mail: angefal@uel.br

* Autor para correspondência
} 


\section{Introdução}

Nesta revisão será abordada a resistência das lagartas da soja, Anticarsia gemmatalis (Hübner, 1818), ao seu nucleopoliedrovírus, Baculovirus anticarsia (AgMNPV), enfocando os hemócitos como um dos componentes do seu sistema de defesa, e suas correlações no "desenvolvimento da habilidade de tolerar doses de inóculo que habitualmente provocariam a enfermidade ou a morte na maior parte dos indivíduos, numa população normal da mesma espécie" (OMOTO; ALVES, 1998).

O controle biológico de insetos desenvolvido no Brasil, utilizando baculovírus, destaca-se como o programa mais importante, devido à extensão de área agrícola tratada (MOSCARDI, 1989, 1999). Com o aumento da utilização de AgMNPV, os estudos iniciais sobre desenvolvimento de resistência de $A$. gemmatalis ao seu baculovírus foram conduzidos no laboratório de Patologia de Insetos da Embrapa Soja, em Londrina, PR, Brasil. A partir de 1991, iniciou-se o programa de investigação para determinar como se desenvolve a resistência ao AgMNPV e delinear estratégias a serem adotadas para permitir o manejo adequado, no caso de provável resistência da lagarta da soja (SOSA-GÓMEZ; MOSCARDI, 2001).

\section{Controle de insetos-praga}

Os insetos constituem um dos grupos mais bem sucedidos na natureza, representando $80 \%$ das espécies do reino animal. Estima-se que existam mais de 2,5 milhões de espécies, sendo que destas apenas um milhão seja conhecida (ALVES, 1998). Os insetos se desenvolvem em quase todos os ambientes e, desde tempos mais remotos, o homem luta contra os insetos-praga que infestam vegetais, especialmente aqueles destinados à alimentação humana e animal. O surgimento de pragas, pode decorrer principalmente da implantação da monocultura, como alternativa de exploração agrícola, que favoreceu o desequilíbrio do ambiente, propiciando a explosão populacional de pragas (BARROS, 1996).
Os danos causados pelos insetos acarretam grandes prejuízos econômicos em todo o globo terrestre, mesmo que somente cerca de $10 \%$ dos insetos conhecidos possam ser considerados pragas da agricultura ou pragas urbanas (GALLO et al., 2002; ALVES, 1998). A economia, o desempenho agronômico, o efeito sobre a saúde humana e ecossistemas, são importantes fatores na seleção de um inseticida para uso em programas de manejo de populações de insetos-praga e muitas vezes são desconsiderados pelo agricultor (BELARMINO, 1992). Assim, gasta-se anualmente no mercado mundial de defensivos agrícolas cerca de US $\$ 1,8$ bilhão em agroquímicos, sendo que inseticidas e acaricidas correspondem a $30 \%$ do total (RIBEIRO; PINEDO, 2001; ALMEIDA; BATISTA FILHO, 2001).

O custo para o desenvolvimento de inseticidas químicos é alto e tem aumentado ao longo dos anos devido à necessidade de novas formulações mais adequadas, o que tem feito crescer o interesse pela pesquisa de inseticidas alternativos, como os bioinseticidas, que são mais baratos no desenvolvimento, apresentam maior tempo de vida útil, devido à dificuldade da praga se tornar resistente, além de serem mais específicos e menos poluentes. Porém, em contrapartida, exigem estudos mais aprofundados no isolamento de novos patógenos, testes de seleção, produção e formulação. Vários países utilizam bioinseticidas para o controle de pragas da lavoura e esses agentes atualmente representam mais de $2 \%$ do mercado de inseticida do mundo (RIBEIRO; PINEDO, 2001; ALMEIDA; BATISTA FILHO, 2001).

O Brasil, por ser um país tropical e com extensas áreas cultivadas pode apresentar prejuízos na produção, variando de 7\% (cevada) a 79\% (girassol) de acordo com a cultura, condições ecológicas, sistemas de cultivo, condições econômicas, entre outros, constituindo-se, portanto, num perigo potencial para as culturas de expressão econômica (GALLO et al., 2002). 
O controle de pragas, principalmente em sistemas de produção agrícola é realizado mediante aplicações freqüentes de inseticidas químicos, como método predominante para reduzir o risco de danos econômicos em lavouras.

Como uma agricultura avançada e racional visa, entre outras coisas, a obtenção de maior produtividade por unidade de área e sanidade da safra, além de baixo custo ecológico (poluição), o uso de produtos químicos como os inseticidas, difundiu-se amplamente para atingir estas finalidades. Entretanto, ficou evidenciado que a utilização cada vez maior desses produtos de alta toxicidade e amplo espectro, apresentam desvantagens, como a poluição do ambiente, a qual pode alterar todo o complexo biótico, afetando plantas, animais e o próprio homem (SILVA, 1989, 1992, 1993; BARROS, 1996; MOSCARDI; SOUZA, 2002).

Atualmente, o controle de pragas em geral, tende a reduzir gradualmente a utilização dos agrotóxicos em decorrência de seus efeitos colaterais, sendo substituídos por métodos alternativos de controle, que consideram os aspectos econômicos e ecológicos, para a solução a médio e longo prazo. Entretanto, observando os mecanismos naturais que impedem a proliferação acentuada de uma espécie, como fatores ambientais e outros organismos, surgiu o controle biológico de pragas. Este consiste na ação dos organismos vivos sobre a população de insetos causadores de danos às plantas, aos animais e ao homem, resultando em uma situação de equilíbrio populacional mais baixa do que prevaleceria na ausência desses agentes (SILVA, 1993).

Entre as alternativas para o uso de agroquímicos, destaca-se a utilização de agentes biológicos de ocorrência natural, como os entomopatógenos, os quais atuam somente sobre a praga, sem afetar ou afetando pouco predadores e parasitas, não deixando resíduos e mantendo, portanto, o equilíbrio ecológico, além de significar na maioria das vezes, economia ao produtor (SOUZA, 2001; RIBEIRO; PINEDO, 2001; SECCHI, 2002).
O uso racional de microrganismos no controle biológico dos insetos-praga e a prevenção de doenças de insetos úteis, como é realizado para a lagarta-daseda Bombyx mori (Linnaeus, 1758), ao meio ambiente atuam de forma harmônica, fazendo com que as populações de insetos permaneçam em níveis não prejudiciais (ALVES, 1998; BARROS, 1996; SOUZA, 2001).

$\mathrm{Na}$ década de 80 foi implantado no Brasil o programa de controle biológico que utiliza o nucleopoliedrovírus (Baculovirus anticarsia) para controle da lagarta da soja (MOSCARDI; SOUZA, 2002; SECCHI, 2002; SOUZA et al., 2002). Desde 1989/90 a aplicação de baculovírus tem oscilado em torno de 1.000.000 ha de área tratada, representando o maior programa de controle biológico do mundo (MOSCARDI; SOSA-GÓMEZ, 1993; SOUZA, 2001).

\section{Baculovírus}

Os baculovírus pertencem à família Baculoviridae, que apresenta dois gêneros, Nucleopoliedrovirus (vírus de poliedrose nuclear - VPN) e Granulovirus (vírus de granulose - VG). São vírus grandes, com DNA circular em dupla fita, que infectam restritivamente os invertebrados e são específicos aos seus hospedeiros. Constituem agentes ideais para o controle de pragas, não afetando insetos benéficos, não apresentando riscos aos vertebrados, incluindo o homem e outros organismos não visados e o meio ambiente. São encontrados principalmente nos insetos, em mais de 600 espécies de insetos, incluindo os lepidópteros, himenópteros, dípteros e coleópteros (SOUZA, 2001).

Essa família tem como principal característica apresentar partículas virais oclusas em corpos protéicos (poliédricos para os VPN e granulares para os VG) e constituir um dos mais conhecidos e bem estudados grupos de vírus, atuando somente sobre a fase larval do inseto, não apresentando efeito direto sobre as fases do ovo, pupa ou adulto (RIBEIRO; PINEDO, 2001; MOSCARDI; SOUZA, 2002; SECCHI, 2002). 
Pelo fato dessas viroses serem específicas para hospedeiros invertebrados e não apresentarem grupos de vírus homólogos para plantas e vertebrados, tornam seu uso reconhecido pela Organização Mundial de Saúde como método seguro e ecologicamente aceitável (MOSCARDI, 1986; OCEPAR, 1994; MOSCARDI; SOUZA, 2002).

$\mathrm{O}$ vírus da poliedrose nuclear multicapsídeo de Anticarsia gemmatalis (AgMNPV) começou a ser aplicado no início da década de 80 pela Embrapa Soja para o controle desta praga da soja, e a sua tecnologia de produção e formulação (pó molhável) já foi transferida para a iniciativa privada (MOSCARDI, 1998). No Brasil, dois outros programas com vírus foram desenvolvidos: o uso de Baculovirus spodoptera (nucleopoliedrovírus Spodoptera frugiperda) para o controle da lagarta do cartucho do milho, produzido em formulação pó molhável pela Embrapa Milho e Sorgo (CRUZ, 2000) e o uso de Baculovirus erinnyis (granulovírus de Erinnyis ello), produzido principalmente na década de 80 pela EPAGRI (SCHIMITT, 1985) e ainda empregado na forma impura, para o controle de mandarová-da-mandioca.

Historicamente, os estudos para o controle da $A$. gemmatalis vêm sendo conduzidos há vários anos e, Moscardi desenvolveu a tecnologia para utilização do vírus da poliedrose nuclear multicapsídeo, Baculovirus anticarsia (AgMNPV), o qual é altamente específico para o controle biológico da lagarta da soja. Atualmente, constitui-se no método mais difundido pelos pesquisadores, mais empregado entre os agricultores e apresenta um custo de $25 \%$ do total gasto com o controle químico (GOMEZ; RUMIATTO, 1987; EMBRAPA, 1997; MOSCARDI, 1998).

A lagarta presente na lavoura tratada ingere junto com as folhas de soja, unidades microscópicas do vírus (poliedros virais). A infecção viral acarreta diminuição gradativa na alimentação e na capacidade de locomoção da lagarta, ficando esta mais exposta à ação de seus predadores naturais. (MOSCARDI; CARVALHO, 1993).
Utilizado em 1,4 milhão de hectares cultivados com soja no Brasil, o AgMNPV proporciona anualmente ao país, uma economia estimada em 13 milhões de reais/ano, uma vez que elimina a aplicação de cerca de 1,2 milhão de litros de inseticidas nas lavouras brasileiras (SOUZA, 2001; EMBRAPA SOJA, 2002). Este fato aliado à crescente exigência mundial de não contaminação ambiental vem aumentando a utilização do bioinseticida, o que tem acarretado uma maior pressão de seleção, sobre a população de insetos no campo.

Entretanto o uso de AgMNPV tem sido limitado devido ao longo espaço de tempo requerido por esses vírus para matar seus hospedeiros. Com a engenharia genética, procura-se acelerar o processo de morte, como também aumentar potencialmente seu uso como agente de controle de insetos (MORAES, MARUNIAK; FUNDERBURK, 1999; MOSCARDI; SOUZA, 2002; SOUZA et al., 2002).

\section{Anticarsia gemmatalis}

O Brasil se destaca mundialmente na produção de soja, sendo esta cultura de grande importância no complexo agroindustrial do país. O incentivo científico e tecnológico para aumentar a qualidade e produtividade deste grão tem sido estrategicamente intensificado, no qual, o combate às diversas pragas que atacam a soja é cada vez mais criterioso, sendo que o manejo integrado de pragas (MIP) vem garantindo sucesso ao seu cultivo.

$\mathrm{Na}$ cultura da soja, várias espécies de insetos são encontradas e geralmente, a que possui maior densidade populacional é a lagarta da soja, Anticarsia gemmatalis (Hübner, 1818) (Lepidoptera: Noctuidae), sendo considerada uma das principais pragas dessa cultura, a qual chega a ocasionar 100\% de destruição da área foliar em períodos de picos populacional, nos meses de janeiro e fevereiro, conforme a região do Brasil (FUNDAÇÃO CARGIL, 1986; MOSCARDI; SOUZA, 2002; SECCHI, 2002). Essa lagarta tem sido registrada 
habitando a cultura da soja desde o início de seu cultivo no Brasil (SILVA, 1989), e é responsável pela aplicação de grande quantidade de inseticidas químicos nesta cultura (SILVA, 1992; BARROS, 1996; MOSCARDI, 1998).

\section{Resistência}

O aumento da pressão de seleção em laboratório demonstrou que a $A$. gemmatalis tem alto potencial para desenvolver resistência ao AgMNPV (ABOT; MOSCARDI; FUXA, 1995; ENGELHARD; VOLKMAN, 1995).

Existem poucos estudos sobre a resistência de insetos a vírus entomopatógenos. No caso de $A$. gemmatalis, existe uma única citação, na qual as populações resistentes ao AgMNPV mantiveram sua susceptibilidade a Bacillus thuringiensis (SOSAGÓMEZ et al., 1992), indicando que este patógeno pode ser usado como uma alternativa de controle.

Fuxa e Richter (1990) citam que a seleção de populações de Spodoptera. frugiperda (SMITH, 1797) resistentes ao NPV de $S$. frugiperda pode afetar a susceptibilidade desta espécie a outros agentes de mortalidade. Assim, a população resistente ao nucleopoliedrovírus de $S$. frugiperda (SfMNPV) mostrou-se pouco susceptível tanto ao $S f G V$, o granulovírus originário da mesma espécie, como ao nucleopoliedrovírus de Autographa californica ( $A c \mathrm{MNPV}$ ), ainda que as taxas de resistência não foram elevadas, variando entre 2,2 a 3,0 vezes.

Estudos indicam que populações de $A$. gemmatalis resistentes ao AgMNPV foram susceptíveis a vários inseticidas sintéticos recomendados para o controle do inseto (COPACHESKI; MOSCARDI apud SOSAGÓMEZ; MOSCARDI, 2001). Na literatura não há dados deste tipo de pesquisa para $A$. gemmatalis, no entanto Ignoffo e Roush (1986) citam que nas espécies de Noctuidae, populações de Heliothis virescens (Fabricius, 1777) resistentes a permetrina e ao metomil ou outras susceptíveis a estes inseticidas, não diferem na sua susceptibilidade ao baculovírus de Heliothis, a Bacillus thuringiensis (Bt) var. kurstaki, ao fungo Nomuraea rileyi e ao microsporídeo Vairimorpha necatrix.

A resistência que os insetos desenvolvem em relação a patógenos é de certa forma, semelhante à resistência aos inseticidas químicos e, como o número de casos de resistência em insetos-praga cresce exponencialmente, é esperado que a A. gemmatalis desenvolva alguma resistência ao seu controle viral (AgMNPV), em condições naturais de campo (ABOT et al., 1996).

Em condições laboratoriais, sob condições ambientais controladas (Temperatura de 25 a $27^{\circ} \mathrm{C}$ e umidade relativa de $80 \%$ ) e sob pressão de seleção, foram obtidas lagartas de $A$. gemmatalis resistentes ao AgMNPV, o que levou os pesquisadores a questionar sobre quais os mecanismos da defesa da lagarta, principalmente de bloqueio, estariam envolvidos nesta resistência (ABOT et al., 1996).

Alguns estudos indicam a possibilidade desta resistência ser atribuída a mecanismos de defesa diferencial(MOSCARDI, 1986; ABOT; MOSCARDI; FUXA, 1995), pois o baculovirus atua somente na fase larval e a susceptibilidade ao vírus decresce à medida que se muda os instares. No quinto instar $A$. gemmatalis apresenta acentuado decréscimo de susceptibilidade, portanto, a eficiência do vírus será maior nos primeiros instares larvais (MOSCARDI, 1986; MOSCARDI; CARVALHO, 1993).

O surgimento de indivíduos resistentes em uma população pode estar condicionado a múltiplos fatores, não somente genéticos, sendo também ecológicos, dependendo intimamente dos métodos de dispersão do inóculo e das características do agente utilizado (SOSA-GÓMEZ; MOSCARDI, 2001).

De acordo com Georghiou e Taylor (1986 apud SOSA-GÓMEZ; MOSCARDI 2001), são considerados como fatores que influenciam no desenvolvimento de resistência a vírus em populações de insetos no campo: a) os fatores genéticos freqüência de alelos resistentes, números de alelos 
resistentes, expressividade e interações dos alelos resistentes, histórico de exposição a outros vírus (epizootias naturais ou individuais) e/ou integração do genoma resistente com outros fatores de "ajuste" ao meio ambiente; b) os fatores biológicos ou ecológicos, como número de gerações por ano, descendência por geração, monogamia, poligamia ou partenogênese, isolamento, mobilidade e migração, monofagia, polifagia, sobrevivência fortuita ou presença de refúgios e c) os fatores operacionais: afinidade do patógeno utilizado com os que ocorrem naturalmente; persistência do patógeno no ambiente (formulação), momento da utilização, grau da precisão de seleção, estágio de desenvolvimento exposto, modo de aplicação e, aplicações limitadas no espaço e tempo.

Considerando esses fatores, segundo SosaGómez e Moscardi (2001), a resistência a um vírus por parte de uma lagarta pode ocorrer de dois modos principais: uma resistência generalizada de todas as células desta lagarta, que são não susceptíveis ao vírus, ou uma resistência localizada nas estruturas responsáveis pela entrada do vírus no organismo, como o tubo digestivo por onde a infecção se inicia.

Dentro do primeiro caso, a restrição ou ponto de bloqueio da replicação viral, pode ser dividido em três níveis fundamentais: a entrada na célula, a replicação do genoma viral e produção de progênie viral, e a liberação desta progênie que servirá para infectar outras células (SOSA-GÓMEZ; MOSCARDI, 2001).

Há relatos sobre o envolvimento do sistema imunológico nos mecanismos de resistência em lepidópteras a diferentes agentes patológicos e/ou parasitas, como por exemplo o caso de Spodoptera exempta (WALKER, 1856) ao seu baculovirus (REESON et al., 1998), porém não são encontrados relatos semelhantes referentes aos de $A$. gemmatalis para o AgMNPV.

\section{Sistema de defesa - Imunologia}

O sucesso dos insetos para se desenvolverem em ambientes repletos de competidores potencialmente parasitas e patógenos, é atribuído à grande eficiência dos seus mecanismos de defesa.

O sistema de defesa dos insetos assemelha-se ao dos vertebrados, sendo composto por barreiras estruturais "passivas" e por respostas ativas, contra elementos estranhos que alcançam a sua hemocele (RATCLIFFE et al., 1985; RENWRANTZ, 1986).

Compreendem-se como barreiras estruturais o rígido exoesqueleto, o sistema digestório e as barreiras respiratórias, que constituem a primeira linha de defesa dos insetos (DUNN, 1986; BULET et al., 1999).

Os insetos cicatrizam rapidamente as suas feridas causadas por trauma ou invasão por parasitas, impedindo a perda fatal de fluidos corporais e a penetração de patógenos oportunistas, processo que envolve independente ou conjuntamente aglutinação ou coagulação celular e coagulação do plasma (RATCLIFFE, 1986; TANADA; KAYA，1993; OMOTO; ALVES, 1998).

O tegumento (CHAPMAN, 1998; BULET et al., 1999) e o trato digestivo (SNODGRASS, 1935; CHAPMAN, 1998; LEVY et al., 2004) representam barreiras físicas importantes contra a infecção e quando estas barreiras são ultrapassadas, os invasores tornam-se expostos a uma variedade de mecanismos celulares e humorais interagindo na defesa do hospedeiro, resultado cooperativo entre o plasma e as células sangüíneas (hemócitos) da hemolinfa (RATCLIFFE et al., 1985; ANGGRAENI; RATCLIFFE, 1991).

Os hemócitos constituem a barreira final do sistema de defesa dos insetos e atuam na coagulação e na cicatrização, na fagocitose, em respostas do tipo encapsulação e nodulação, fatores antimicrobianos naturais (síntese induzida de peptídeos e proteínas antimicrobianas) (TANADA; KAYA, 1993; LAVINE; STRAND, 2002) e fatores bioquímicofisiológicos, que são respostas coordenadas direta ou indiretamente pelos vários tipos de hemócitos (RATCLIFFE; ROWLEY, 1975, 1979, 1987; BARRACO; MENEZES, 1985; GUPTA, 1985), 
dependente do número e dos tipos de hemócitos presentes na hemolinfa, garantindo o sucesso do sistema imunológico (RUSSO; BREHÉLIN; CARTON, 2001).

Fatores de comportamento e fisiológicos que podem alterar a susceptibilidade de insetos a moléculas químicas podem também afetar a susceptibilidade a agentes microbianos. Porém, devido à natureza dos agentes microbianos, certos mecanismos de resistência a patógenos são bastante diferentes daqueles que regulam a resistência aos produtos químicos (SOSA-GÓMEZ; PEREIRA; ALVES, 1998).

No sistema imunológico dos insetos não foram evidenciadas imunoglobulinas específicas (anticorpos monoclonais) para reconhecimento de antígenos (WILLOTT et al., 1994; NIERE et al., 1999; SILVA, 2002). Assim, torna-se importante a caracterização e a purificação de peptídeos antimicrobianos produzidos em resposta a infecções causadas por vírus, bactéria ou fungos em várias espécies de insetos, juntamente com informações da biotecnologia, principalmente de natureza genética, propiciando novos discernimentos sobre a organização e a regulação do sistema imunológico dos mesmos.

Sabe-se hoje que os insetos possuem um sistema de reconhecimento de patógenos capaz de ativar um complexo de moléculas sinalizadoras e de coordenar a expressão de vários genes (FRANC; WHITE, 2000). Além disso, o conhecimento das respostas imunológicas que estão presentes na hemolinfa pode fornecer informações valiosas para o delineamento de novas formas de controle biológico.

A habilidade de reconhecer a presença de um organismo ou de uma substância estranha é fundamental para o sistema imunológico de qualquer indivíduo. Nos insetos, a natureza das moléculas de reconhecimento não está bem definida. Alguns receptores associados à membrana dos hemócitos e outros solúveis na hemolinfa são capazes de reconhecer e aglutinar diretamente os patógenos, enquanto outros podem induzir a ativação de cascatas proteolíticas (PATHAK, 1993a).
As aglutininas constituem um grupo heterogêneo de moléculas de glicoproteínas, não-imunoglobulinas e que não apresentam atividades enzimáticas, identificadas pela capacidade de se ligarem a resíduos de carboidratos específicos, como também a açúcares livres ou partes de oligo ou polissacarídeos (FELTON; GATEHOUSE, 1996). Podem estar presentes em microrganismos, plantas, vertebrados e invertebrados, podendo ser identificadas/detectadas por sua capacidade de aglutinar diferentes tipos de células alvo, tais como hemácias, bactérias, fungos, protozoários, espermatozóides, dentre outros (OLAFSEN, 1986). Quando estas aglutininas têm determinado o tipo de carboidrato específico de ligação, são então denominadas de lectinas.

A interação das aglutininas e a ativação da cascata profenoloxidase são os mediadores no processo de reconhecimento de patógenos e parasitóides (BOUCIAS; PENDLAND, 1993; KAWASAKI; KUBO; NATORI, 1996; WILSON et al., 1999).

As lectinas são uma classe de glicoproteínas que participam de muitos processos biológicos, que se ligam a glicolipídios, glicoproteínas ou polissacarídeos na superfície de células animais, causando a sua aglutinação e/ou precipitação. As unidades glicídicas dessas moléculas têm grande potencial para codificar informações biológicas (PATHAK, 1993b).

Nos insetos, as lectinas têm sido detectadas na hemolinfa, agindo como opsoninas (proteínas que se fixam e transformam as propriedades da superfície dos patógenos), aglutinando os microrganismos, e como receptores na membrana dos hemócitos, auxiliando-os no reconhecimento e na fagocitose dos tecidos (GREGÓRIO, 1990; PATHAK, 1993b). As lectinas são produzidas durante os processos infecciosos, nas injúrias do tegumento e na degradação dos tecidos durante os estágios de desenvolvimento (BOUCIAS; PENDLAND, 1993; DRIF; BREHÉLIN, 1994; KAWASAKI; KUBO; NATORI, 1996).

$\mathrm{Na}$ maioria dos insetos estudados, as moléculas de lectinas formam pontes entre os hemócitos e 
células conduzindo galactose em suas membranas, sendo que várias moléculas já foram purificadas e caracterizadas em lepidópteros e ortópteros (DRIF; BREHÉLIN, 1994; CHEN; ROWLEY; RATCLIFFE, 1998).

\section{Hemócitos}

$\mathrm{Na}$ literatura, encontram-se poucos trabalhos com hemócitos de insetos quando se considera o elevado número estimado de insetos existentes e daqueles economicamente importantes. Desses trabalhos, as principais ordens estudadas são: Lepidoptera, Himenoptera, Coleoptera e Diptera (CHAPMAN, 1998).

O estudo dos hemócitos através da microscopia óptica gerou controvérsias quanto à identificação e à nomenclatura dos mesmos, bem como sua relação com os mecanismos de defesa celular (GUPTA, 1985; RICHARDS; DAVIES, 1994; STRAND; JOHNSON, 1996). Essas controvérsias são devidas à diversidade de insetos, às diferentes funções que podem assumir ao longo do desenvolvimento, à sua labilidade durante as diferentes metodologias empregadas e aos parâmetros empregados na classificação, como velocidade de degranulação, fragilidade citoplasmática, capacidade de emitir pseudópodes e realizar fagocitose, bem como a aderência a outras células ou superfícies (KURIHARA; SHIMAZU; WAGO, 1992a, 1992b; FALLEIROS, 1995; ANDRADE et al., 2003).

Gupta $(1979,1985)$ em ampla revisão da literatura, uniformizou a nomenclatura dessas células e classificou os principais tipos presentes em várias ordens de insetos: prohemócito (PR), plasmatócito (PL), granulócito (GR) e oenocitóide (OE). Tipos adicionais também foram descritas: coagulócito $(\mathrm{CO})$, adipohemócito (AD), esferulócito (ES), podócito (PO) e vermiforme (VE).

A hemolinfa de lepidópteros, de modo geral, apresenta os tipos clássicos de hemócitos: PL, GR, OE, ES, PR (RIBEIRO; SIMÕES; BREHÉLIN,
1996; STRAND; JOHNSON, 1996; RICHARDS; EDWARDS, 1999), bem como pode apresentar as células vermiformes (FALLEIROS, 1995; FALLEIROS; BOMBONATO; GREGÓRIO, 2003). Em lagartas de A. gemmatalis foram descritos seis tipos de células: PL, GR, ES, OE, PR e VE, e um sétimo semelhante à célula esfoliativa de mucosa de mamíferos, raramente observado, e denominado de célula esfoliativa (EF) (ANDRADE et al., 2003). Faraldo (2000) descreveu este tipo celular em hemolinfa dos dípteros, mosca-do-berne (Dermatobia hominis) (LINNAEUS JR, 1781) e mosca-varejeira (Chrysomya megacephala) (FABRICIUS, 1794), em lâminas a fresco sob contraste de fase em ambas as espécies e em microscopia eletrônica de varredura para D. hominis.

Os hemócitos PR são considerados por diversos autores como stem cells, ou seja, células que originam outros tipos celulares. Exibem alto índice mitótico, e no período pós-embrionário dos hemócitos, sua quantificação não passa de $5 \%$ do total de células (GUPTA, 1979, 1985; GONÇALVES, 1983).

Estudos sobre estágios de diferenciação dos hemócitos em vários insetos, realizados por Gupta $(1979,1985)$ permitiram a elaboração de um esquema no qual os PR são as stem cells que originam os PL e estes os GR. Os GR são células pluripotentes e dão origem aos $\mathrm{AD}, \mathrm{VE}$ e $\mathrm{ES}$, que pode ser expresso no seguinte esquema principal: $\mathrm{PR} \rightarrow \mathrm{PL} \rightarrow \mathrm{GR} \rightarrow \mathrm{ES}$, já que AD e VE não são encontrados na maioria das espécies. Falleiros (1995) e Falleiros, Bombonato e Gregório (2003) constataram ultraestruturalmente em lagartas da broca-da-cana, Diatraea saccharalis (FABRICIUS, 1794), PL e GR em estágios de divisão mitótica, além disso, observaram hemócitos com aspectos intermediários entre PR-PL e PL-GR, sugerindo assim que essas células multiplicam-se e diferenciam-se na hemolinfa, durante o desenvolvimento larval. Em culturas de PR de Bombyx mori (LINNAEUS, 1758), o bicho da seda, Yamashita e Iwabuchi (2001) mostraram que aproximadamente 43\% dessas células, diferenciam-se em PL, GR e ES, confirmando assim sua pluripotencialidade. 
PL e GR são as células que possuem maior capacidade fagocítica, tanto in vitro quanto in vivo, utilizando enzimas lisossomais para destruir o invasor (RATCLIFFE; ROWLEY, 1975, 1987; FALLEIROS; GREGÓRIO, 1995). Quando as partículas ou invasores possuem dimensões ou número considerável, estes hemócitos participam da encapsulação celular e da formação de nódulo (GUPTA, 1985; TANADA; KAYA, 1993).

Os OE são as células produtoras da enzima fenoloxidases (IWAMA; ASHIDA, 1986; KURIHARA; SHIMAZU; WAGO, 1992 a; FALLEIROS, 1995) sendo que, para Schmit, Rowley e Ratcliffe (1977) em algumas espécies de insetos, a presença desta enzima é detectada em GR; para Preston e Taylor (1970) em PL e para Hoffmann, Porte e Joly (1970) em CO. A fenoloxidase pode também ser encontrada no plasma, como em Manduca sexta (LINNAEUS, 1763; SAUL; BIN; SUGUMARAN, 1987).

Os ES são células relacionadas à renovação tecidual, transporte de substâncias como hormônios, produção de algumas proteínas da hemolinfa, participação na defesa contra bactérias e nutrição (GONÇALVES, 1983; RATCLIFFE et al., 1985).

Os AD possuem gotas de lipídio em seu citoplasma como reserva (GUPTA, 1979, 1985; CHAPMAN, 1998) e sua identificação é muito controversa, pois uma provável hipótese é de que são células resultantes de uma variação de PL ou GR, que acumularam lipídio (BOMBONATO; GREGÓRIO, 1995; FALLEIROS, 1995; FARALDO, 2000).

Na hemolinfa de alguns insetos, foi constatada a ocorrência de $\mathrm{CO}$, que seriam responsáveis pela liberação de substâncias desencadeadoras do processo de coagulação. Nas espécies em que não existem $\mathrm{CO}$, esse processo pode estar sendo iniciado pela liberação de fatores provindos de GR ou ES (GRÉGOIRE; GOFFINET, 1979).

As VE há muito geram controvérsia sobre sua existência. Analisando a hemolinfa de Spodoptera litura (FABRICIUS, 1775), Kurihara, Shimazu e Wago (1992a) propuseram que poderiam ser coagulócitos (CO) e então seriam denominados de podócitos (PO). Gupta (1985), descreveu as VE como estágios celulares diferenciados dos PL, e justificou essa discussão sobre sua identificação, como sendo devida à semelhança ultraestrutural que possuem entre si, podendo indicar que sua origem poderia ser a partir de PL. Entretanto, Falleiros (1995) e Falleiros, Bombonato e Gregório (2003) argumentam que as VE encontradas em lagartas de Diatraea saccharalis não poderiam ser um tipo celular apenas diferenciado de PL, mas um tipo distinto com características morfológicas, citoquímicas e funcionais bastante individualizadas.

Foi detectada por Falleiros (1995) a presença de fosfatase ácida e vacúolos em VE, mas não foi observado sinal de fagocitose depois de inoculação de partículas inertes, contribuindo para a distinção destas células dos PL, conhecidas como células fagocíticas. Nunes (2001) demonstrou em experimento com $D$. saccharalis parasitadas pela vespa Cotesia flavipes (Cameron, 1891), que as VE aumentavam o número de vacúolos e persistia na positividade para fosfatase ácida e trimetafosfatase, mas sem indícios de fagocitose, mantendo assim seu papel desconhecido no sistema de defesa.

Os hemócitos circulam livremente na hemolinfa, mas após a invasão de bactérias, fungos, vírus ou protozoários, rapidamente migram para o local da infecção, onde fagocitam e destroem os invasores (SILVA; GARY; RAU, 2000; RUSSO; BREHÉLIN; CARTON, 2001; SILVA, 2002). A encapsulação é um processo desencadeado quando patógenos invasores muito grandes ou numerosos para serem fagocitados, são envolvidos em agregados multicelulares, podendo formar cápsulas ou nódulos ao redor do invasor (RATCLIFFE et al., 1985; PECH; TRUDEAU; STRAND, 1995; MEYERFERNANDES et al., 2000).

Quando a concentração de patógenos é muito grande, os hemócitos se agregam e formam nódulos a fim de imobilizá-los e removê-los da circulação. 
Contra larvas e ovos de endoparasitóides que são depositados na hemocele e não podem ser fagocitados e nem isolados em nódulos, os insetos se defendem formando cápsulas (DUNN, 1986; STRAND; $\mathrm{PECH}, 1995)$. O encapsulamento é influenciado por fatores genéticos e fisiológicos tanto do hospedeiro quanto do parasitóide.

A fagocitose é um processo de resposta celular primária na defesa, que ocorre contra vírus, bactérias, protozoários, fungos ou material inerte particulado, tanto in vivo como in vitro (RATCLIFFE et al., 1985; CHIANG; GUPTA; HAN, 1988; MEYERFERNANDES et al., 2000). Envolve as seguintes fases: quimiotaxia, aderência, ingestão e destruição do agente estranho (RATCLIFFE, 1982).

Os organismos aprisionados são destruídos por um sistema de complexo enzimático, denominado de sistema profenoloxidase (proPO), sendo que a principal enzima ativada é a fenoloxidase, sintetizada pelos oenocitóides (OE) (KURIHARA; SHIMAZU; WAGO, 1992a; STRAND; PECH, 1995; RIBEIRO; SIMÕES; BREHÉLIN, 1996). O sistema de proPO constitui um dos mais importantes componentes do sistema de defesa. A fenoloxidase faz parte de uma cascata enzimática ativada pelos granulócitos (GR) através da exocitose de fatores sinais, acarretando a síntese de proteínas que aumentam a adesividade dos plasmatócitos (PL) ao invasor e intensificando a exocitose de outros GR, ou ainda, a produção de quinonas tóxicas e o processo de melanização que inativam ou matam o invasor (RATCLIFFE; ROWLEY, 1979; SÖDERHÄLL， 1982; RATCLIFFE et al., 1985).

A quantidade e os tipos de hemócitos são fatoreschave para o sucesso dessas reações. Alterações na contagem dessas células são os primeiros sinais de parasitismo (RUSSO; BREHÉLIN; CARTON, 2001).

Além de participarem dos processos de defesa, os hemócitos também desempenham a função de armazenar e distribuir nutrientes como carboidratos, fosfolipídios e proteínas para todo o corpo do inseto, atuam nos processos de remodelação de tecidos durante as mudas, participam do transporte de hormônios e metabólitos, e da reprodução (CROSSLEY, 1979; SCHIMIDT-NIELSEN, 1999).

Os hemócitos não possuem função de transportar oxigênio, assim, a troca gasosa tecidual é realizada diretamente pelo sistema traqueal. A hemolinfa possui função hidrostática devida à presença de íons inorgânicos como sódio, cloreto, magnésio e potássio, este último em altas concentrações, que são os reguladores de osmolaridade na hemocele (GALLO et al., 2002; RICHARDS; DAVIES, 1994; SCHIMIDT-NIELSEN, 1999).

Em diferentes espécies de insetos, o número e os tipos de hemócitos podem apresentar-se muito variáveis. Por exemplo, dentro da mesma espécie esse número pode variar ao longo do desenvolvimento do inseto desde sua fase imatura (larval), nas ecdises e nos adultos (CLARK; CHADBOURNE, 1960; ARNOLD; HINKS, 1976).

Os fluidos corporais dos insetos possuem uma variedade de fatores de defesa humoral, naturais ou induzíveis. Os fatores naturais de defesa são constituídos por aglutininas, lisozimas e outras lisinas, bactericidinas não-lisozima, enzimas lisossomais e fatores de imobilização. Os fatores induzíveis de defesa são verificáveis poucas horas após a injeção de antígeno. Um destes fatores, denominado hemolina, possui considerável homologia (38\%) com as imunoglobulinas. Tal fator pode estar envolvido no reconhecimento de moléculas estranhas, de modo similar às aglutininas e aos componentes do sistema proPO (GÖTZ; BOMAN, 1985; RATCLIFFE et al., 1985; RATCLIFFE, 1986).

\section{Considerações finais}

É conhecido que apesar da grande eficácia do sistema de defesa nos insetos, alguns patógenos conseguem ludibriar e sobreviver à grande bateria defensiva do hospedeiro. Essas reações de escape do patógeno são consideradas as bases principais para o desenvolvimento de um bom agente para o controle biológico do inseto. 
No caso da lagarta da soja, o AgMNPV, consegue evadir-se bem, rompendo as barreiras defensivas e desarmando os mecanismos envolvidos nas reações de defesa de $A$. gemmatalis.

No entanto, a presença de lagartas resistentes ao patógeno (AgMNPV), é um indicativo de alterações responsáveis por uma resposta defensiva muito mais eficaz, aprimorada e agressiva, que não permite ao vírus a sua completa replicação, impedindo a sua continuidade de ciclo.

Nos últimos anos, tem havido um grande progresso no conhecimento das defesas imunológicas dos insetos. A biodiversidade desses organismos tem proporcionado modelos importantes para estudos de suas estratégias de defesa, as quais podem fornecer informações relevantes para o combate de pragas agrícolas e vetores de doenças, bem como para o estudo da imunologia geral.

\section{Referências}

ABOT, A. R.; MOSCARDI, F.; FUXA, J. R.; SOSA-GÓMEZ, D. R.; RICHTER, A. R. Development of resistance by Anticarsia gemmatalis from Brazil and the United States to a nuclear polyhedrosis virus under laboratory selection pressure. Biological Control, Orlando, v.9, p.126-130, 1996.

ABOT, A. R.; MOSCARDI, F.; FUXA, J. R. Susceptibility of populations of Anticarsia gemmatalis (Lepidoptera: Noctuidae) from Brasil and the United States to a nuclear polyhedrosis virus. Journal of Entomological Science, Tifton, v.30, p.62-69, 1995.

ALMEIDA, J. E. M.; BATISTA FILHO, A. Banco de microrganismos entomopatogênicos. Biotecnologia Ciência e Desenvolvimento, Brasília, v.20. p.30-33, 2001.

ALVES, S. B. Patologia e controle microbiano: vantagens e desvantagens. In: (Ed.). Controle microbiano de insetos. 2.ed. Piracicaba: FEALQ, 1998. p.21-37

ANDRADE, F. G.; NEGREIRO, M. C. C.; GREGÓRIO, E. A.; MOSCARDI, F.; FALLEIROS, Â. M. F. Hemocytes of Anticarsia gemmatalis (Hübner) (Lepidoptera: Noctuidae) larvae: morphological and quantitative studies. Acta Microscopica, Caracas, v.12, n.1, p.59-64, 2003.

ANGGRAENI, T.; RATCLIFFE, N. A. Studies on cell-cell co-operation during phagocytosis by purified haemocyte populations of the wax moth, Galleria mellonella. Journal of Insect Physiology, Oxford, v.37, n.6, p.453-460, 1991.
ARNOLD, J. W.; HINKS, C. F. Haemopoiesis in Lepidoptera I: the multiplication of circulating haemocytes. Canadian Journal of Zoology, Ottawa, v.54, p.1003-1012, 1976.

BARRACO, M. A.; MENEZES, H. Mecanismos celulares de defesa em insetos. Ciência e Cultura, São Paulo, v.37, n.2, p.237-250, fev. 1985.

BARROS, N. M. Utilização do fungo Nomuraea rileyi para o controle da lagarta da soja. In: MEDEIROS, L.; ARAÚJO, M. C. G. P.; COELHO, G. C. (Org.). Interações ecológicas \& biodiversidade. Ijuí: Unijuí, 1996. p.225-233.

BELARMINO, L. C. Avaliação econômica de inseticidas biológicos. Pesquisa Agropecuária Brasileira, Brasília, v.27, p.371-389, 1992.

BOMBONATO, M. T.; GREGÓRIO, E. A. Estudo morfológico e quantitativo dos hemócitos em larvas de Diatraea sacharalis (Fabricius) (Lepidoptera, Pyralidae). Revista Brasileira de Zoologia, São Paulo, v.12, n.4, p.867879, 1995.

BOUCIAS, D. G.; PENDLAND, J. C. The galactose binding lectin from the beet armyworm, Spodoptera exígua: distribution and site of synthesis. Insect Biochemistry and Molecular Biology, Oxford, v.23, n.2, p.233-242, 1993.

BULET, P.; HETRU, C.; DIMARCQ, J.; HOFFMANN, D. Antimicrobial peptides in insects; structure and function. Developmental and Comparative Immunology. New York, v.23. p.329-344, 1999.

CHAPMAN, R. F. The insects: structure and function. 4.ed. Cambridge: Cambridge University Press, 1998. 770p.

CHEN, C.; ROWLEY, A. F.; RATCLIFFE, N. A. Detection, purification by immunoaffinity chromatography and properties of â-1,3-glucan-specific lectins from the sera of several insect species. Insect Biochemistry and Molecular Biology, Oxford, v.28, p.721-731, 1998.

CHIANG, A. S.; GUPTA, A. P.; HAN, S. S. Arthropod immune system: I-comparative light and electron microscopic accounts of immunocytes and others hemocytes of Blattella germanica (Dictyoptera: Blattellidae). Journal of Morphology, New York, v.198, p.257-267, 1988.

CLARK, E. W.; CHADBOURNE, D. S. The haemocytes of nondiapause and diapause larvae and pupae of the pink bollworm. Annals of the Entomological Society of America, College Park, v.53, p.682-685, 1960.

CROSSLEY, A. C. S. Biochemical and ultrastructural aspects of synthesis, storage, and secretion in hemocytes. In: GUPTA, A. P. (Ed.). Insect hemocytes: development, forms, function and techniques. Cambridge: Cambridge University Press, 1979. p.423-473. 
CRUZ, I. Utilização do baculovírus no controle da lagartado-cartucho do milho, Spodoptera frugiperda. In: MELO, I. S.; AZEVEDO, J. L. (Ed.). Controle biológico. Jaguariúna: Embrapa-Meio Ambiente, 2000. v.3, p.201-230.

DRIF, L.; BREHÉLIN, M. Purification and characterization of an agglutinin from the hemolymph of Locusta migratoria (Orthoptera). Insect Biochemical and Molecular Biology, Oxford, v.24, n.3, p.283-289, 1994.

DUNN, P. E. Biochemical aspects of insect immunity. Annual Review of Entomology, Stanford, v.31, p.321-339, 1986.

EMBRAPA.. Recomendações técnicas para a cultura da soja no Paraná (1997/98). Londrina, 1997. p.141-53.

EMBRAPA. CNPSo. Manejo de pragas. Disponível em: $<$ http://www.cnpso.embrapa.br>. Acesso em: 2 set. 2002.

ENGELHARD, E. K.; VOLKMAN, L. E. Developmental resistance in fourth instar Trichoplusia ni orally inoculated with Autographa californica M nuclear polyhedrosis virus. Virology, New York, v.209, p.384-389, 1995.

FALlEIROS, A. M. F. Células sanguíneas de Diatraea saccharalis (Lepidoptera: Pyralidae): estudo citoquímico ultraestrutural e à microscopia de varredura. 1995. Tese (Doutorado em Ciências Biológicas) - Instituto de Biociências, Universidade Estadual Paulista "Júlio de Mesquita Filho", Botucatu, 1995.

FALLEIROS, A. M. F.; GREGÓRIO,E. A. Hemócitos fagocitários em larvas de Diatraea saccharalis (Fabricius) (Lepidoptera, Pyralidae). Revista Brasileira de Zoologia, São Paulo, v.12, n.4, p.751-758, 1995.

FALLEIROS, A. M. F.; BOMBONATO, M. T. S.; GREGÓRIO, E. A.. Ultrastructural and quantitative studies of hemocytes in the sugarcane borer Diatraea saccharalis (Fabricius) (Lepidoptera: Pyralidae). Brazilian Archives of Biology and Technology, Curitiba, v.46, n.2, p.287-294, 2003.

FARALDO, A. C. Hemócitos de díptera economicamente importantes: análise qualitativa, quantitativa e funcional. 2000. Dissertação (Mestrado em Ciências Biológicas) Instituto de Biociências, Universidade Estadual Paulista "Júlio de Mesquita Filho", Botucatu, 2000.

FELTON, G. W.; GATEHOUSE, J. A.. Antinutritive plant defense mechanisms. In: LEHANE, M. J.; BILLINGSLEY, P. F. (Ed.). Biology of insect midgut. Londres: Chapman \& Hall, 1996. p.373-416.

FRANC, N. C.; WHITE, K. Innate recognition in insect immunity and development: new approaches in Drosophila. Special issue: Innate recognition systems in host defence. Microbes and Infection, Paris, v.2, n.30, p.243-250, 2000.

FUNDAÇÃO CARGIL. Pragas da soja. In: A soja no Brasil central: revista e ampliada. Campinas: CARGIL, 1986. p.215-233.
FUXA, J. R.; RICHTER, A R.. Response of nuclear polyhedrosis virus-resistant Spodptera frugiperda larvae to other pathogens and to chemical insecticides. Journal of Invertebrate Pathology, San Diego, v.55, p.272-277, 1990.

GALLO, D.; NAKANO, O.; SILVEIRA-NETO, S.; CARVALHO, R. P. L.; BATISTA, G. C. de; BERTIFILHO, E.; PARRA, J. R. P.; ZUCCHI, R. A.; ALVES, S. B.; VENDRAMIM, J. D.; MARCHINI, L. C.; LOPES, J. R. S.; OMOTO, C. Entomologia agrícola. Piracicaba: FEALQ, 2002.

GONÇALVES, S. M. Estudo dos elementos figurados da hemolinfa de Diatraea saccharalis (Lepidoptera: Pyralidae) nos periodos de pré-pupa, pupa e adulto. 1983. Dissertação (Licenciatura em Ciências Biológicas) Instituto Básico de Biologia Médica e Agrícola, Universidade Estadual Paulista "Júlio de Mesquita Filho", Botucatu, 1983.

GÖTZ, P.; BOMAN, H. G. Insect immunity. In: KERKUT, G. A.; GILBERT, L. I. (Ed.).Comprehensive insect physiology, biochemistry and pharmacology. Great Britain: Pergamon Press, 1985. p.453-485.

GRÉGOIRE, C. H.; GOFFINET, G. Controversies about the coagulocytes. In: GUPTA, A. P. (Ed.). Insects hemocytes: development, forms, functions and techniques. Cambridge: Cambridge University Press, 1979. p.189-229.

GREGÓRIO, E. A. Aglutininas, fatores líticos e o sistema de profenoloxidase em Rodnius prolixus e Triatoma infestans: estudo in vitro. 1990. Tese (Livre Docência) - Instituto de Biociências de Botucatu, Universidade Estadual Paulista "Júlio de Mesquita Filho", Botucatu, 1990.

GUPTA, A. P. Cellular elements in the hemolymph. In: KERKUT, G. A.; GILBERT, L. I. (Ed.) Comprehensive Insect Physiology, Biochemistry and Pharmacology. v.3. Oxford: Pergamon Press, 1985. p.401-451.

. Hemocyte types: their structures, synonymies, interrelationships, and taxonomic significance. In:

Insect Hemocytes: development, forms, functions and techniques. New York: Cambridge University Press, 1979. p. $85-127$.

HOFFMANN, J. A.; PORTE, A.; JOLY, P. On the localization of phenoloxidase activity in coagulation of Locusta mignatoria (L.) (Orthoptera). Comptes Rendus Hebdomadaires des Seances de l Academie des Sciences, Paris, v.270, p.629-631, 1970.

IGNOFFO, C. M.; ROUSH, R. T. Susceptibility of permethrin- and methomyl-resistant strains of Heliothis virescens (Lepidoptera: Noctuidae) to representative species of entomopathogens. Journal of Economical Entomology, Maryland, v.79, p.173-179, 1986. 
IWAMA, R.; ASHIDA, M. Biosynthesis of the prophenoloxidase in hemocytes of larval hemolymph of silkworm, Bombyx mori. Insect Biochemistry, London, v.16, n.3, p.547-555, 1986.

KAWASAKI, K.; KUBO, T.; NATORI, S. Presence of the Periplaneta lectin-related protein family in the American cockroach Periplaneta americana. Insect Biochemistry and Molecular Biology, Oxford, v.26, n.4, p.355-364, 1996.

KURIHARA, Y.; SHIMAZU, T.; WAGO, H. Classification of hemocytes in the common cutworm, Spodoptera litura (Lepidoptera: Noctuidae): I-phase microscopic study. Applied Entomology and Zoology, Tokio, v.27, p.225-235, 1992a.

KURIHARA, Y.; SHIMAZU, T.; WAGO, H. Classification of hemocytes in the common cutworm, Spodoptera litura (Lepidoptera: Noctuidae): II-possible roles of granular plasmatocytes and oenocytoids in the cellular defense reactions. Applied Entomology and Zoology, Tokio, v.27, p.237-242, $1992 b$.

LAVINE, M. D.; STRAND, M. R.. Insect hemocytes and their role in immunity. Insect Biochemistry and Molecular Biology, Oxford, v.32, p.1295-1309, 2002.

LEVY, S. M.; FALLEIROS, A. M. F.; GREGÓRIO, E. A.; ARREBOLA, N. R.; TOLEDO, L. A. The larval midgut of Anticarsia gemmatalis (Hübner) (Lepidoptera: Noctuidae): light and electron microscopy studies of the epithelial cells. Brazilian Journal of Biology, São Carlos, v.64, n.3B, p.633-638, 2004.

MEYER-FERNANDES, J. R.; LANZ-MENDOZA, H.; GONDIM, K. C.; WILlOTT, E.; WELlS, M. A. Ectonucleotide diphosphohydrolase activities in hemocytes of larvae Manduca sexta. Archives of Biochemistry and Biophysics, New York, v.382, n.1, p.152$159,2000$.

MORAES, R. R.; MARUNIAK, J. E.; FUNDERBURK, J.E. Methods for detection of Anticarsia gemmatalis nucleopolyhedrovirus DNA in soil. Applied and Environmental Microbiology, Washington, v.65, n.6, p.2307-2311, 1999.

MOSCARDI, F. Utilização de vírus para controle da lagarta da soja. In: ALVES, S. B.(Ed.). Controle microbiano de insetos. São Paulo: Manole, 1986. p.188-202.

. The use of viruses for pest control in Brazil: the case of the nuclear polyhedrosis virus of the soybean caterpillar, Anticarsia gemmatalis. Memórias do Instituto Oswaldo Cruz, São Paulo, v.4, p.51-56, 1989.

. Utilização de vírus entomopatogênicos em campo. In: ALVES, S. B. (Ed.). Controle microbiano de insetos. 2.ed. Piracicaba: FEALQ, 1998. p.509-539.
. Assessment of the application of baculoviruses for control of Lepidoptera. Annual Review of Entomology, Stanford, v.44, p.257-258, 1999.

MOSCARDI, F.; CARVALHO, R. C. Z. Consumo e utilização de soja por Anticarsia gemmatalis Hüb. (Lepidoptera: Noctuidae) infectada, em diferentes estádios larvais, por seu vírus de poliedrose nuclear. Anais da Sociedade Entomológica do Brasil, Jaboticabal, v.22, p.267-80, 1993.

MOSCARDI, F.; SOSA-GÓMEZ, D. R. A case study in biological control: soybean defoliating caterpillars in Brazil. In: BUXTON, I.; SHIBLES, D. R..; FORSBERG, R. A.; BLAD, B. L; ASAY, K. H.; PAULSEN, G. M.; WILSON, R. F. (Ed.). International Crop Science. Madison: Crop Science Society of America, 1993. p.115-119.

MOSCARDI, F.; SOUZA, M. L. Baculovírus para o controle de pragas. Biotecnologia Ciência e Desenvolvimento, Brasília, v.24. p.22-29, 2002.

NIERE, M; MEIBLITZER; DETTLOFF, M; WEISE, C; ZIEGLER, M; WIESNER, A. Insect immune activation by recombinant Galleria mellonella apolopophorin III. Biochimica et Biophysica Acta, Amsterdam, v.1433. p.1626, 1999.

NUNES, C. C. C. Caracterização citoquímica e ultraestrutural dos hemócitos de Diatraea saccharalis (Lepidoptera: Pyralidae) parasitada pela vespa Cotesia flavipes (Hymenoptera: Braconidae). 2001. Dissertação (Mestrado em Ciências Biológicas) - Instituto de Biociências de Botucatu, Universidade Estadual Paulista "Júlio de Mesquita Filho", Botucatu.

OLAFSEN, J. A. Invertebrate lectins: biochemical heterogeneity as a possible key to their biological function. In: BREHELIN, M. (Ed). Immunity in invertebrates: cells, molecules and defence reactions. Heidelberg: Spring-Verlag, 1986. p.94-111.

OMOTO, C.; ALVES, S. B. Mecanismos de defesa de insetos contra entomopatógenos. In: ALVES, S. B. (Ed.). Controle microbiano de insetos. 2.ed. Piracicaba: FEALQ, 1998. p.55-73.

OCEPAR. Recomendações técnicas para a cultura da soja no Paraná, 1994/95. Cascavel, 1994. (Boletim Técnico).

PATHAK, J. P. N. Cell-mediated defence reactions in insects. In: PATHAK, J. P. N.(Ed.). Insect Immunity. India: Kluwer Academic Publishers, 1993a. p.47-58.

Haemagglutinins (lectins) in insects. In:

Insect Immunity. India: Kluwer Academic Publishers, 1993b. p.149-169. 
PECH, L. L.; TRUDEAU, D.; STRAND, M. R. Effects of basement membranes on behavior of hemocytes from Pseudoplusia includens (Lepidoptera: Noctuidae): development of an in vitro encapsulation assay. Journal of Insect Physiology, Oxford, v.41, n.9, p.801-807, 1995.

PRESTON, J. W.; TAYLOR, R. L. Observations on the phenoloxidase system in the haemohymph of the cockroach Leucophae maderae. Journal of Insect Physiology, Oxford, v.16, p.1729-1744, 1970.

RATCLIFFE, N. A. Cellular defence reaction of insects. Fortschritte der Zoologie, Jena, v.27, p.223-244, 1982.

RATCLIFFE, N. A. Insect cellular immunity and the recognition of foreignness. In: LACKIE, A. M. (Ed.). Zoological Symposium: immune mechanisms in invertebrate vectors. London: The Zoological Society of London, 1986. p.21-43.

RATCLIFFE, N. A.; ROWLEY, A. F. Cellular defence reations of insect hemocytes in vitro: phagocytosis in a new suspension culture system. Journal of Invertebrate Pathology, San Diego, v.26, p.225-233, 1975.

Role of hemocytes in defence against biological agents. In: GUPTA, A. P. (Ed.). Insect hemocytes: development, forms, function and techniques. Cambridge: Cambridge University Press, 1979. p.331-314.

RATCLIFFE, N. A.; ROWLEY, A. F. Insect responses to parasites and other pathogens. In: JOULSBY, E. J. L. (Ed.). Immune responses in parasitic infection: immunology, immunopathology and immunoprophylaxis, protozoa, arthropods and invertebrate. Florida: C. R. C. Press, 1987. p.123-254.

RATCLIFFE, N. A.; ROWLEY, A. F.; FITZGEALD, S. W.; RHODES, C. P. Invertebrate immunity: basici concepts and recent advances. International Review of Cytology, New York, v.97, p.183-279, 1985.

REESON, A. F.; WILSON, K.; GUNN, A.; HAILS, R. S.; GOULSON, D. Baculovirus resistance in the noctuid Spodoptera exempta is phenotypically plastic and responds to population density. Proceedings of the Royal Society of London, London, v.265, p.1787-1791, 1998.

RENWRANTZ, L. Lectins in molluscs and arthropods: their occurrence origin and roles in immunity. In: LACKIE, A. M. (Ed). Immunity mechanisms in invertebrate vectors. Oxford: Claredon Press, 1986. p.81-93.

RIBEIRO, C.; SIMÕES, N.; BREHÉLIN, M.. Insect immunity: the haemocytes of armyworm Mythimna unipuncta (Lepidoptera: Noctuidae) and their role defence reactions in vivo and in vitro studies. Journal of Insect Physiology, Oxford, v.42, n.9, p.815-822, 1996.
RIBEIRO, B. M. R.; PINEDO, F. J. R. Baculovírus recombinante para controle de praga. Biotecnologia Ciência e Desenvolvimento, Brasília, v.22. p.50-58, 2001.

RICHARDS, E. H.; EDWARDS, J. P. Parasitization of Lacanobia oleracea (Lepidoptera: Noctuidae) by the ectoparasitic wasp, Eulophus pernicornis: effects of parasitization, venom and starvation on host haemocytes. Journal of Insect Physiology, Oxford, v.45, p.1073-1083, 1999.

RICHARDS, O. W.; DAVIES, R. G. IMM'S general textbook of entomology. 10.ed. London: Chapman \& Hall, 1994.418p.

RUSSO, J.; BREHÉLIN, M.; CARTON, Y. Haemocyte changes in resistant and susceptible strains of Drosophila melanogaster caused by virulent and avirulent strains of the parasitic wasp Leptopilina boulardi. Journal of Insect Physiology, Oxford, v.47, p.167-172, 2001.

SAUL, S. J.; BIN, L.; SUGUMARAN, M. The majority of prophenoloxidase in the hemolymph of Manduca sexta is present in the plasma and not in the haemocytes. Developmental and Comparative Immunology, New York, v.11, p.479-486, 1987.

SCHIMITT, A. T. Eficiência da aplicação do Baculovirus erinnyis no controle do mandarová da mandioca. Florianópolis: EMPASC, 1985. (Comunicado Técnico, 88).

SCHMIDT-NIELSEN, K. Fisiologia animal: adaptação e meio ambiente. 5.ed. São Paulo: Santos, 1999.

SCHMIT, A. R.; ROWLEY, A. F.; RATCLIFFE, N. A.. The role of Galleria mellonella hemocytes in melanin formation. Journal of Invertebrate Pathology, San Diego, v.29, p.232-234, 1977.

SECCHI, V. A. Baculovírus, mais do que uma grande descoberta: uma revolucionária alternativa aos agrotóxicos. Agroecologia e Desenvolvimento Rural Sustentável, Porto Alegre, v.3, n.3, p.49-54, 2002.

SILVA, C. C. Aspectos do sistema imunológico dos insetos. Biotecnologia Ciência e Desenvolvimento, Brasília, v.24, p.68-72, 2002.

SILVA, C.; GARY, B. D.; RAU, M. E. Interaction of hemocytes and prophenoloxidase system of fifth instar nymphs of Acheta domesticus with bacteria. Developmental and Comparative Immunology, New York, v.24, p.367-379, 2000.

SILVA, M. T. B. da. Reestudo de diversas técnicas de controle da lagarta da soja. In: FUNDACEP FECOTRIGO. Culturas de verão: resultados de pesquisa. Cruz Alta: FUNDACEP FECOTRIGO, 1989. p.122-127.

SILVA, M. T. B. da. Controle da lagarta da soja (Anticarsia gemmatalis Hübner, 1818. Lepidoptera: Noctuidae), 2. 
Baculovirus anticarsia. Ciência Rural, Santa Maria, v.22, n.3, p.261-265, 1992.

SILVA, M. T. B. da. Controle da lagarta da soja (Anticarsia gemmatalis Hübner, 1818. Lepidoptera: Noctuidae), 4. controle biológico natural. Ciência Rural, Santa Maria, v.23, n.2, p.127-132, 1993.

SNODGRASS, R. E. Principles of insect morphology. New York: MacGraw-Hill, 1935.

SÖDERHÄLL, K. The prophenoloxidase activating system and melanization a recognition mecanism of arthropods: a review. Development Comparative Immunology, New York, v.6, p.601-611, 1982.

SOSA-GÓMEZ, D. R.; ABOT, A. R.; MOSCARDI, F.; PARO, F.E., SOLDORIO, I. Susceptibilidade de diferentes instares de Anticarsia gemmatalis ao Bacillus thuringienses e avaliação da resistência cruzada em populações resistentes ao Baculovirus anticarsia. In: SIMPÓSIO DE CONTROLE BIOLÓGICO, 3., 1992, Jaguariúna. Resumos... Jaguariúna: CNPDA, 1992. p.193.

SOSA-GÓMEZ, D. R.; PEREIRA, R. M.; ALVES, S. B. Environmental impact of entomopathogens: impacto ambiental de entomopatógenos. In: ALVES, S. B. (Ed.). Controle microbiano de insetos. 2.ed. Piracicaba: FEALQ, 1998.p.1075-1095.

SOSA-GÓMEZ, D.; MOSCARDI, F. Resistencia de lepidópteros a los nucleopoliedrovirus: el caso de Anticarsia gemmatalis-AgMNPV. In: CABALLERO, P.; LÓPEZ-FERBER, M.; WILLIAMS, T.(Ed.). Los baculovirus y sus aplicaciones como bioinsecticidas en el control biológico de plagas. Espanha: Universidad Pública de Navarra, 2001.p.451-478.
SOUZA, M. L. Utilização de microrganismos na agricultura. Biotecnologia Ciência \& Desenvolvimento, Brasília, n.21, jul./ago. 2001.

SOUZA, M. L. S.; CASTRO, M. E. B; SILHER, W.; RIBEIRO, Z. M. A.; MOSCARDI, F. Caracterização de baculovírus utilizados no controle de pragas. Biotecnologia Ciência e Desenvolvimento, Brasília, v.24, p.18-20, 2002.

STRAND, M. R.; JOHNSON, J. A. Characterization of monoclonal antibodies to hemocytes of Pseudoplusia includens. Journal of Insect Physiology, Oxford, v.42, n.1, p.21-31, 1996.

STRAND, M. R.; PECH, L. L. Immunological basis for compatibility in parasitoid-host relationships. Annual Review of Entomology, Stanford, v.40, p.31-56, 1995.

TANADA, Y.; KAYA, H. K. Insect pathology. San Diego: Academic Press, 1993.

WILLOTT, E.; TRENCZEK, T.; THROWER, L.; KANOST, M. R. Immunochemical identification of insect populations monoclonal antibodies distinguish four major hemocyte types in Manduca sexta. European Journal of Cell Biology, Stuttgartv, v.65, p.417-423, 1994.

WILSON, R.; CHEN, C.; RATCLIFFE, N. A.; CHEN, C. W. Innate immunity in insects: the role of multiple, endogenous serum lectins in the recognition of foreign invaders in the cockroach, Blaberus discoidalis. Journal of Immunology, Baltimore, v.162, p.1590-1596, 1999.

YAMASHITA, M.; IWABUCHI, K. Bombyx mori prohemocyte division and differentiation in individual microcultures. Journal of Insect Physiology, Oxford, v.47, p.325-331, 2001. 
